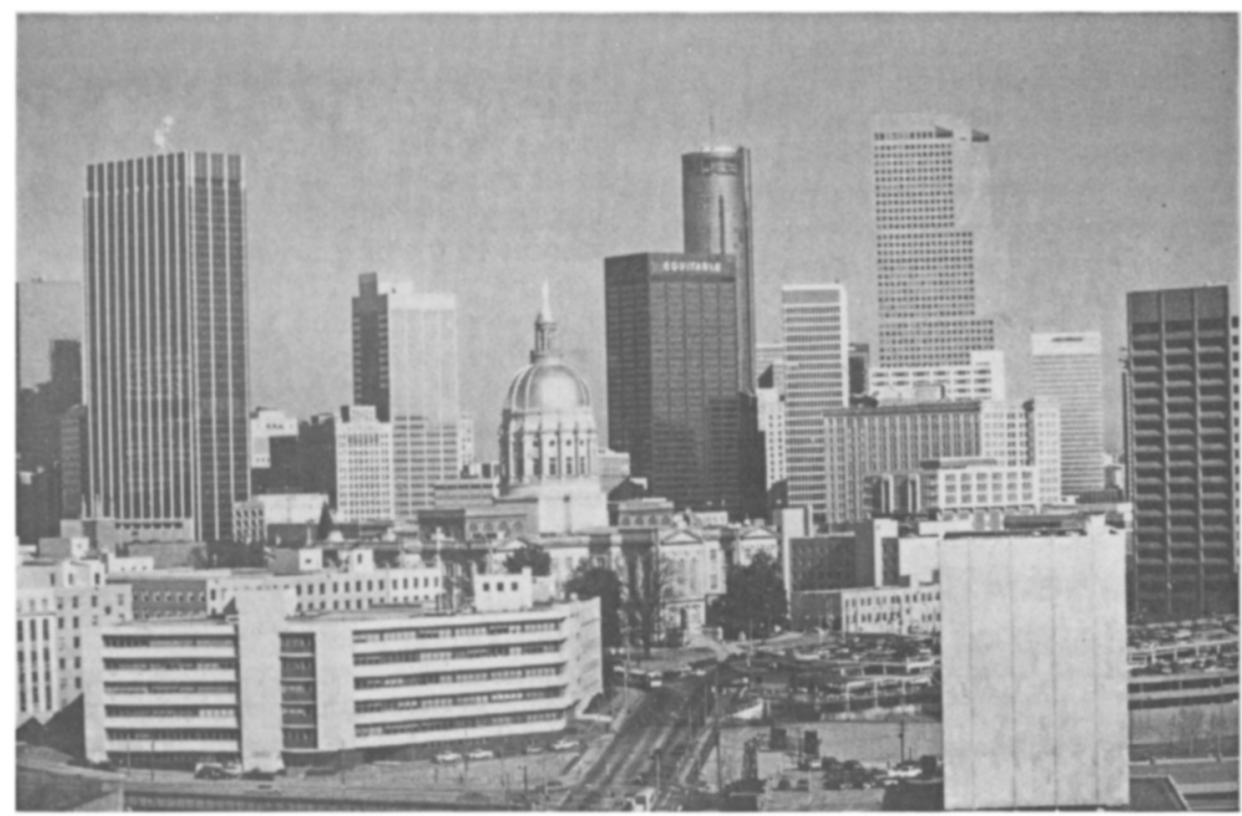

Atlanta, Georgla site of the APSA Annual Meeting.

\section{Plan Now for Atlanta Annual Meeting}

The Atlanta annual meeting promises to be a stimulating meeting at unusually good hotel and travel rates. For the first time Organized Sections of the Association will assume responsibility for organizing panels within their subject matter. In addition six sections of the program will focus on special themes: Thomas Hobbes, The French Revolution, Political Science in Washington, The Civil Rights Act of 1964 , The Bill of Rights, and Party Realignment.

The program featuring 34 sections will be enhanced by the Gaus lecture, the presidential address of Lucian Pye, the triennial Lasswell symposium, as well as two special plenary sessions. One plenary session promises to be a real mind teaser, an evening of political trivia. Come and stump the panel of experts!

The Association is developing short courses that promise to draw on the unique history of Atlanta; short courses on the Civil War, southern politics, the civil rights movement. Look to future issues of $P S$ for additional information.

Excellent hotel and travel rates will make attending the Atlanta annual meeting easy. Delta Airlines will offer a special convention rate of 5 percent below their best fares to Atlanta. Likewise, the Atlanta Hilton, located in the heart of Peach Tree Plaza, will offer APSA members rates of $\$ 61$ for single rooms and $\$ 83$ for double rooms.

\section{News About APSA Organized Sections}

The Section on Political Organizations and Parties has a new newsletter editor. $\mathrm{He}$ is John Green, The Ray Bliss Institute, University of Akron, Akron, $\mathrm{OH} 44325$ 1904.

The Section on International Security and Arms Control, which expects to receive official sanction from the Council soon, is actively seeking members. Those 